Bond University

Research Repository

\title{
Physical fitness, sex considerations, and academy graduation for law enforcement recruits
}

Lockie, Robert; Dawes, Jay; Dulla, Joseph; Orr, Rob Marc; Hernandez, Erika

Published in:

Journal of Strength and Conditioning Research

DOI:

10.1519/JSC.0000000000003844

Licence:

Other

Link to output in Bond University research repository.

Recommended citation(APA):

Lockie, R., Dawes, J., Dulla, J., Orr, R. M., \& Hernandez, E. (2020). Physical fitness, sex considerations, and academy graduation for law enforcement recruits. Journal of Strength and Conditioning Research, 34(12), 33563363. https://doi.org/10.1519/JSC.0000000000003844

\footnotetext{
General rights

Copyright and moral rights for the publications made accessible in the public portal are retained by the authors and/or other copyright owners and it is a condition of accessing publications that users recognise and abide by the legal requirements associated with these rights.
}

For more information, or if you believe that this document breaches copyright, please contact the Bond University research repository coordinator. 
Physical Fitness, Sex Considerations, and Academy Graduation for Law Enforcement

\section{Recruits}

This is a non-final version of an article published in final form in Lockie, R., Dawes, J., Dulla, J., Orr, R. M., \& Hernandez, E. (2020). Physical fitness, sex considerations, and academy graduation for law enforcement recruits. Journal of Strength and Conditioning Research. https://doi.org/10.1519/JSC.0000000000003844 


\section{ABSTRACT}

This study investigated the influence of fitness on academy graduation, and any between-sex differences, in law enforcement recruits. Data collected at the start of four training academies were retrospectively analyzed, including: age, height, and body mass; waist circumference; waist-to-hip ratio; grip strength; vertical jump (VJ); 75-yard pursuit run; 2-kg medicine ball throw (MBT); push-ups, sit-ups, and arm ergometer revolutions in $60 \mathrm{~s}$; and 20-m multistage fitness test (20MSFT) shuttles. Recruits were categorized into graduated (GRAD=269) and separated (did not graduate; $\mathrm{SEP}=42$ ) groups. SEP recruits were not split according to separation reasons, just whether they did or not. This categorization also occurred for males $(\mathrm{GRAD}=228, \mathrm{SEP}=32)$ and females $(\mathrm{GRAD}=41, \mathrm{SEP}=10)$. Independent samples t-tests calculated between-group differences for all recruits combined, males, and females. Correlations and stepwise linear regression calculated relationships between the data and graduation. The t-test $(p \leq 0.016)$ and correlation $(r= \pm 0.137-0.296, p<0.05)$ data indicated SEP recruits (both sexes combined) were older, and performed poorer in every fitness test except grip strength and VJ. SEP males were older and performed poorer in all tests except grip strength $(p \leq 0.009)$. SEP females scored lower in the arm ergometer $(p=0.008)$. The regression equation for all recruits found that age, 20MSFT (aerobic fitness), MBT (upper-body power), and arm ergometer (upper-body endurance) were academy graduation predictors $\left(r^{2}=0.169\right.$, $p<0.001)$. For the male recruits, the predictors were age, MBT, and 20MSFT $\left(r^{2}=0.182\right.$, $p \leq 0.001)$; for female recruits, arm ergometer and 20MSFT $\left(r^{2}=0.213, p \leq 0.003\right)$. Recruits should improve multiple fitness aspects, including muscular endurance, power, and aerobic fitness, to enhance graduation potential.

Key words: aerobic fitness; arm ergometer; police; power; tactical; upper-body endurance; 20m multistage fitness test 


\section{INTRODUCTION}

Law enforcement can be a physically challenging profession, with a variety of tasks required of officers. Some of the tasks that can stress an officer's fitness include defensive tactics (38), rescuing civilians or partners, vaulting obstacles, and pursuing and apprehending suspects $(7,21)$. There can also be high mental stress imparted through working in law enforcement $(15)$. Even in tasks where there is limited physical activity (e.g. checking bona fides, such as a person's identification), the unpredictability that exists when interacting with the general population can lead to a pronounced physiological response (e.g. increased heart rate) (11). Due to these demands, law enforcement recruits routinely complete academy training before becoming sworn officers. In addition to learning the necessary rules, regulations, laws and procedures required for their job and agency, academy training is designed to mentally and physically prepare recruits for the job $(21,25,39)$.

However, not all recruits will graduate from the academy. This has been referred to as separation (i.e. the recruit either does not meet expected standards, they get injured and physically cannot complete the training, or they voluntarily resign from the law enforcement agency [LEA]) (25). Recruits that separate can create a significant financial burden to a LEA $(39,42)$. Accordingly, some authors have investigated the influence physical fitness may have on academy graduation for law enforcement recruits $(10,25,37,42)$. If certain fitness characteristics can be identified in successful or unsuccessful recruits, then this information can be used for initial fitness testing for the agency, or as an indicator for those recruits who may need specific training either prior to or during an academy. For example, Shusko et al. (42) found that prior to the academy, Massachusetts-based recruits who completed fewer pushups in $60 \mathrm{~s}$ and had a slower $2.4-\mathrm{km}$ run time, were more likely to separate. Orr et al. (37) documented that lower-body power measured by a vertical jump (VJ) was a predictor of injury or illness in Australian police recruits. Lockie et al. (25) investigated whether fitness was a 
contributing factor to reasons for separation in Californian law enforcement recruits. Recruits that separated for personal reasons, or due to physical training failures or injury, completed fewer shuttles in the 20-m multistage fitness test (20MSFT; a measure of aerobic fitness) (25). Additionally, recruits that separated due to physical training failures or injury were slower in a change-of-direction speed test called the 75-yard pursuit run (75PR), which was a foot pursuit simulation (25). Although there can be different reasons for why a recruit may separate from an academy (25), anecdotally training staff have noted that fitness does provide an indication of how a recruit approaches other aspects of their life. For example, given that the academy requires physical and mental discipline $(21,25,39)$, if a recruit is ill-disciplined with maintaining their fitness, they may be ill-disciplined with their study habits as well. Therefore, there is great value in analyzing physical fitness relative to graduation and separation in law enforcement recruits, regardless of potential reasons behind separation.

It is also important to recognize is that recruit classes typically feature a mixture of men and women with a wide range of fitness capacities $(24,29)$. None of the afore-mentioned studies closely investigated whether the fitness characteristics relative to academy graduation for each sex was different. This is despite numerous studies documenting clear differences between male and female law enforcement recruits in physical fitness tests $(3,5,28,32)$. Greater understanding of female law enforcement recruits is especially pertinent, considering many agencies want to hire and retain more women $(12,13,45)$. Dawes et al. (10) examined initial fitness testing data from male and female police recruits, and found that recruits who separated were older, and had lesser performance in all fitness tests used by the agency; push-ups and situps completed in $60 \mathrm{~s}$, a vertical jump (VJ), and the 20MSFT. The best fitness predictors for male recruits were push-up scores and VJ height. Unfortunately, Dawes et al. (10) could not specifically analyze the fitness predictors for female recruits due to their low numbers $(n=10)$ within the sample $(\mathrm{N}=99)$. Indeed, investigating a larger recruit sample with more females 
could allow for a more specific analysis as to the influence of sex on academy graduation. The disparity between the sexes is a common issue for law enforcement research, because of the general disparity between males and females in the law enforcement profession $(3,5,21,24,25,27,29,31)$. Nonetheless, because of the importance and need for agencies to hire and retain more women $(12,13,45)$, any research that places a specific focus on female law enforcement recruits (regardless of the final sample) has great value to practitioners in this field. Furthermore, a testing battery with different, potentially more occupationally-specific, measures of physical fitness metrics could also elucidate useful information regarding the qualities that contribute to recruit graduation.

Therefore, the purpose of this cross-sectional study was to analyze the non-causal relationships physical fitness may have on academy graduation, and whether there were specific characteristics relative to each sex that predicted graduation status. This is essential information for law enforcement training staff. Although there can be different reasons for academy separation, physical fitness can be an influencing factor for a number of these reasons (25). Additionally, and similar to Dawes et al. (10), a further goal of this research was to develop a prediction model based on fitness testing data to ascertain which recruits were more likely to graduate from an academy. Recruits were stratified into those that graduated (GRAD) or separated (SEP) from a training academy. In line with previous research $(10,25,42)$, it was hypothesized that recruits who were superior in all fitness tests would be more likely to graduate from the academy.

\section{METHODS}

\section{Experimental Approach to the Problem}

Retrospective analysis of pre-existing data for recruits belonging to four classes from one LEA was conducted. The study was modeled on that from Dawes et al. (10); however, the current 
research had different fitness tests that were used by LEA in this study, in addition to a larger sample size. As stated, recruits were stratified into GRAD (recruits who completed and graduated from the academy) and SEP (recruits who separated and did not complete the academy for any reason) groups, and independent samples t-tests were used to determine any differences between the groups for all recruits combined, males, and females. Recruits could separate for a variety of reasons, including injury, academic or physical training failures, or personal reasons (25). It should be noted that physical fitness alone did not dictate whether a recruit did not complete academy. However, given how physical fitness could influence different reasons for separation $(10,25,42)$, recruits were placed in the SEP group regardless of their reason for separation. GRAD recruits completed a 22-week training academy, which featured a minimum of 36 physical training sessions were required (30). All four academy classes completed more physical training sessions than the minimum. However, each academy class varied due to differences in class timetables, and training location and staff availabilities, which was typical for this LEA. Point bi-serial correlations and stepwise linear regression were then used to determine relationships between fitness and graduation in the recruits. The dependent variables for this study were: age, height, and body mass; waist circumference (WC) and waist-to-hip ratio (WHR); combined grip strength from both hands; VJ height; 75PR time; 2-kg medicine ball throw (MBT) distance; push-up repetitions; sit-up repetitions; arm ergometer revolutions; and 20MSFT shuttles.

\section{Subjects}

Data were collected by the staff from one US-based LEA in the week preceding academy training for all the classes that were analyzed, and were released with consent from that organization. This sample comprised 311 recruits (age: $27.50 \pm 6.08$ years, height: $1.73 \pm 0.09$ m, body mass: $79.75 \pm 13.75 \mathrm{~kg})$, including 260 males $(27.48 \pm 6.24$ years; height: $1.75 \pm 0.08$ 
$\mathrm{m}$; body mass: $83.01 \pm 12.26 \mathrm{~kg})$ and 51 females $(27.59 \pm 5.29$ years; height: $1.62 \pm 0.06 \mathrm{~m}$; body mass: $63.09 \pm 7.43 \mathrm{~kg}$ ). The characteristics of the subjects in this study, in addition to the ratio between the sexes, was typical of law enforcement populations $(3,5,20$ $22,24,25,27,29,31,32)$. The four training cohorts completed their academy within a calendar year in southern California. Any strength and conditioning programs prior to the academy were generally completed voluntarily at the individual-level only by recruits (31). Based on the archival nature of this study, the institutional ethics committee approved the use of pre-existing data (HSR-17-18-370). The study still conformed to the recommendations of the Declaration of Helsinki (44).

\section{Procedures}

The data in this study were collected by staff working for one LEA, using procedures established in the literature $(3,5,22,24,31,32)$. The staff were all trained by a certified tactical strength and conditioning facilitator who verified the proficiency of the staff members. Prior to testing, each recruit's age, height, and body mass were recorded. Height was measured using a portable stadiometer (Seca, Hamburg, Germany), while body mass was recorded by electronic digital scales (Omron Healthcare, Kyoto, Japan). All tests were conducted outdoors on concrete or asphalt surfaces at the LEA's training facility on a day scheduled by the LEA staff. Testing occurred between 0900-1400 (9:00am-2:00pm) depending on recruit availability. Recruits typically did not eat in the $2-3$ hours prior to their testing session as they were completing employee-specific documentation for the LEA. The weather conditions for testing were typical of the climate of southern California. Although conducting testing outdoors is not ideal, there was no available indoor testing facility available for this LEA and these procedures were adopted by staff from the LEA at all levels $(3,5,21,22,24,25,28-32)$. Recruits rotated 
through the tests in small groups of 3-4, except for the 20MSFT which was completed in groups of 14-16, and were permitted to consume water as required during testing.

\section{Waist Circumference (WC) and Waist-to-Hip Ratio (WHR)}

Greater WC and WHR has been associated with poorer fitness test performance in law enforcement recruits (31), and thus was included in this study. A thin-line metric tape measure (Lufkin, Apex Tool Group, Maryland) was used to measure WC and WHR for all recruits. The protocols used in this study followed established procedures (31). WC was measured in $\mathrm{cm}$ at the narrowest part of the waist just superior to the naval (i.e. the narrowest part of the waist between the umbilicus and xiphoid process), while hip circumference was measured at the greatest posterior extension of the hip. WHR was calculated by dividing WC by hip circumference.

\section{Grip Strength}

Grip strength for each hand was measured by a hand grip dynamometer (Takei Scientific Instruments, Japan) with procedures adapted from previous research $(7,8,28,31)$. As per Dawes et al. (7), the hand grip dynamometer was adjusted so that the base of the first metacarpal and the middle four fingers were in contact with the handle. Recruits kept their testing arm by their side throughout the assessment, and squeezed the handle as hard as possible for approximately $2 \mathrm{~s}(28,31)$. Two attempts were completed for each hand and recorded to the nearest kg, with the left hand tested first (31). The best score for each hand was summed together to provide the combine grip strength score that was used for analysis.

\section{Vertical Jump (VJ)}

A Vertec apparatus (Perform Better, Rhode Island, USA) was used to measure the VJ, which 
provided an indirect metric for lower-body power. Established protocols were used to measure VJ height $(2,22,23,31)$, and these procedures have very high test-retest reliability $(r>0.99)(2)$. The recruit initially stood side-on to the Vertec (on the recruit's dominant side), reached upward as high as possible, and fully elevated the shoulder to displace as many vanes as possible, all while keeping their heels on the ground. The last vane moved became the zero reference. The recruit then jumped as high as possible, with no preparatory step, and height was recorded from highest vane moved. No restrictions were placed on the range of countermovement during the jump. VJ height was calculated in inches by subtracting the standing reach height from the jump height, before being converted to $\mathrm{cm}$. Each subject completed two trials, with a recovery time between trials of approximately $60 \mathrm{~s}$, and the best trial was used for analysis.

\section{5-Yard Pursuit Run (75PR)}

The 75PR was designed to simulate a foot pursuit for a law enforcement officer $(3,5,20,24)$, and provided a measure of change-of-direction speed. In a similar population, the 75PR has been shown to have high trial-to-trial reliability (intra-class correlation coefficient [ICC] $=$ 0.85) (20). The structure for the 75PR is shown in Figure 1. The recruit completed five linear sprints about a square grid (each side was $12.1 \mathrm{~m}$ ), while completing four, $45^{\circ}$ direction changes zig-zagging across the grid. Recruits also stepped over three barriers that were $2.44 \mathrm{~m}$ long and $0.15 \mathrm{~m}$ high that simulated curbs during three of the five sprints. Time was recorded via a stopwatch, from the initiation of movement at the start, until the recruit crossed the finish line. Stopwatch timing was the standard measurement technique for this test $(3,5,20)$, and testers trained in the use of stopwatch timing procedures for running tests can record reliable data (17). Two trials were completed with at least 2 minutes rest between trials, and the fastest trial was analyzed. 
***INSERT FIGURE 1 ABOUT HERE***

\section{Medicine Ball Throw (MBT)}

The MBT was used to indirectly measure upper-body power. Established procedures were utilized $(22,23,31)$, which has high test-retest reliability $(r>0.95)(16)$. Recruits sat on the ground with their head, shoulders, and lower back against a concrete wall, and projected a 2$\mathrm{kg}$ medicine ball (Champion Barbell, Texas, USA) as far as possible using a two-handed chest pass. The ball was lightly dusted with chalk to assist with grip, and to also mark the landing spot of the ball (23). The measurement taken, using a standard tape measure, was the perpendicular distance from the wall to the chalk-marking closest to the wall made by the ball. Two trials were completed, with a recovery time between trials of approximately $60 \mathrm{~s}$, and the best trial was analyzed.

\section{Push-ups}

Upper-body muscular endurance was assessed via a maximal push-up test where recruits completed as many repetitions as possible in $60 \mathrm{~s}$. This is a standard test in law enforcement, and the protocol for this test followed established law enforcement procedures $(21,24,28,29,31)$. Maximal push-up tests have high trial-to-trial reliability $(\mathrm{ICC}=0.95)(41)$. A tester placed a fist on the floor directly under the recruit's chest to ensure they descended to an appropriate depth. Although there are some limitations with this approach, this ensured recruits descended to the required push-up depth (28). All female recruits were partnered with a female tester. On the start command, the tester began the stopwatch and the recruit flexed their elbows and lowered themselves until their chests contacted the tester's fist before they 
extended their elbows to return to the start position. Recruits performed as many push-ups as possible using this technique in the allotted time period.

\section{Sit-ups}

Abdominal muscular endurance was assessed via the sit-up test, where the recruits completed as many repetitions as possible in $60 \mathrm{~s}$. Similar to the push-up test, the sit-up test is a standard test in law enforcement $(21,24,28,29,31)$. Maximal sit-up tests have high trial-to-trial reliability $(\mathrm{ICC}=0.92)(41)$. The recruits laid on their backs with their knees flexed to $90^{\circ}$, heels flat on the ground, and arms crossed over the chest. The feet were held to the ground by a tester who also counted the repetitions. On the start command, recruits raised their shoulders from the ground while keeping their arms crossed over the chest and touched their elbows to their knees. The recruit then descended back down until their shoulder blades contacted the ground. Recruits completed as many repetitions as possible using this technique within the 60-s time period.

\section{Arm Ergometer}

The arm ergometer test was used as an assessment of upper-body endurance $(3,5,31)$, and was performed on an arm ergometer (Monark 881E, Vansbro, Sweden) positioned on a table. A longer version of this maximal arm ergometer test has been found to have high test-retest reliability $(r>0.90)(14)$. The procedures as exactly defined by the LEA in their testing manual (which was used as part of the hiring process, so needed to be followed exactly no matter when this test was conducted) were used for this test, and this has featured in previous research $(3,5,24,31)$. The recruit completed 10 revolutions of the arm ergometer prior to the test to set the workload to 50 watts and allow the recruit to become familiar to the equipment. Before starting the trial, the recruit moved one handle to the start position marked on the ergometer so 
that one complete revolution took place before the counter registered ' 1 '. The counter was then reset to zero. After the tester initiated the test, recruits completed as many revolutions as possible in $60 \mathrm{~s}$. The final number of revolutions that were completed at the 60 -s mark was then read off the counter.

\section{0-m Multi-Stage Fitness Test (20MSFT)}

The 20MSFT was used to measure maximal aerobic capacity in the recruits and was conducted outdoors on an asphalt surface. Although these were not the best conditions to conduct the 20MSFT, this was the only available space at the LEA's training facility and has been, and remains, the standard venue used at this facility. This test has very high reliability (ICC $=0.96$ ) (1), and has been utilized in numerous law enforcement populations with standard procedures (7,10,30-32). Recruits were required to run back and forth between two lines spaced $20 \mathrm{~m}$ apart, which were indicated by markers. The speed of running for this test was standardized by prerecorded auditory cues (i.e. beeps) played from an iPad handheld device (Apple Inc., Cupertino, California) connected via Bluetooth to a portable speaker (ION Block Rocker, Cumberland, Rhode Island). The speaker was located in the center of the running area, and positioned in such a way that it would not interfere with the recruits. The test was terminated when the recruit was unable to reach the lines twice in a row in accordance with the auditory cues. This test was scored according to the final level and stage the recruit was able to achieve, and the level and stage results was used to calculate the total number of shuttles completed.

\section{Statistical Analysis}

Information as to whether recruits completed academy and graduated, or did not and were separated, were provided by staff from the LEA (25). From this, recruits were categorized into GRAD (recruits who completed and graduated from the academy) and SEP (recruits who 
separated and did not complete the academy for any reason) groups. Statistical analyses were processed using the Statistics Package for Social Sciences (Version 26.0; IBM Corporation, New York, USA). Normality of the fitness test data for each sex was confirmed by visual analysis of the Q-Q plots $(4,19,36)$. The analysis for this study was adapted from Dawes et al. (10). Descriptive statistics (mean \pm standard deviation $[S D]$ ) were calculated for each variable. Independent samples t-tests were used to calculate any differences between GRAD and SEP groups for all recruits combined, males, and females. The overall level of significance was set a priori at $p<0.01$ due to the number t-tests performed and to limit family-wise error (10).

Following this, a point bi-serial correlation analyses was used to determine if significant relationships existed between academy graduation and the fitness tests, with significance set a priori at $p<0.05$. This statistical method was used to determine relationships between continuous variables and those that are binary (i.e. academy graduation or separation) (10). Recruits who graduated were labeled with ' 1 '; recruits who separated with ' 0 '. The correlation strength was designated as: an $r$ between 0 to \pm 0.3 was small; \pm 0.31 to \pm 0.49 , moderate; \pm 0.5 to \pm 0.69 , large; \pm 0.7 to \pm 0.89 , very large; and \pm 0.9 to \pm 1 near perfect for relationship prediction (18). Finally, stepwise multiple regression was conducted to see if age, anthropometrics, or fitness predicted graduation in all recruits combined, males, and females (10). The independent variables can be continuous or categorical (dummy coded as appropriate). Dummy coding was used to provide categorical predictor variables in the regression for this study (43). Dummy coding used only ones and zeros to represent group membership (GRAD or SEP for both sexes combined, males, and females) (43). As noted, these methods were used by Dawes et al. (10) in a similar investigation. 


\section{RESULTS}

Table 1 displays the data for all recruits combined. The SEP group were significantly older than the GRAD group. The SEP group also had lesser performance compared to the GRAD group in the following fitness tests: 75PR, MBT, push-ups, sit-ups, arm ergometer, and 20MSFT. When considering the male recruits (Table 2), the SEP group was also significantly older than the GRAD group. Further, male recruits in the SEP group have lesser performance in all fitness tests except for grip strength. For the female recruits (Table 3), the only significant difference between the GRAD and SEP groups was the arm ergometer; the SEP group completed fewer revolutions than the GRAD group.

\section{***INSERT TABLES 1-3 ABOUT HERE***}

The correlation data for all recruits combined, males, and females are displayed in Table 4. For all recruits, the following variables related to academy graduation: younger age, taller height, greater VJ height and MBT distance, faster 75PR, and more push-up repetitions, sit-up repetitions, arm ergometer revolutions, and 20MSFT shuttles. The strength of the correlations were all small. The correlation data for the male recruits exhibited the same significant relationships, minus that for height and with the addition of the VJ. All the significant relationships for male recruits were also small. The female recruits demonstrated only one significant relationship; academy graduation had a small correlation with greater arm ergometer revolutions.

***INSERT TABLE 4 ABOUT HERE***

14

This is a non-final version of an article published in final form in Lockie, R., Dawes, J., Dulla, J., Orr, R. M., \& Hernandez, E. (2020). Physical fitness, sex considerations, and academy graduation for law enforcement recruits. Journal of Strength and Conditioning Research. https://doi.org/10.1519/JSC.0000000000003844 
The stepwise linear regression for all recruits found that age, the 20MSFT (aerobic fitness), MBT (upper-body power), and arm ergometer (upper-body endurance) were the predictors of academy graduation $\left(r=0.411 ; r^{2}=0.169\right.$; adjusted $\left.r^{2}=0.158\right)$. For the male recruits, the predictors of academy graduation were age, MBT, and 20MSFT $\left(r=0.426 ; r^{2}=\right.$ 0.182 ; adjusted $\left.r^{2}=0.172\right)$. Regarding the female recruits, the predictors of academy graduation were the arm ergometer and 20MSFT $\left(r=0.462 ; r^{2}=0.213\right.$; adjusted $\left.r^{2}=0.180\right)$. The final regression equations for predicting academy graduation were:

$$
\begin{aligned}
& \text { All recruits }=1.371+(0.014 \times \text { age })+(-0.003 \times 20 M S F T \text { shuttle score })+(- \\
& 0.033 \times \text { MBT score })+(-0.002 \times \text { arm ergometer score }) \\
& \text { Male recruits }=1.336+(0.014 \times \text { age })+(-0.065 \times \text { MBT score })+(-0.003 \times \\
& \text { 20MSFT shuttle score }) \\
& \text { Female recruits }=2.780+(-0.011 \times \text { arm ergometer score })+(-0.007 \times 20 M S F T \\
& \text { shuttle score })
\end{aligned}
$$

\section{DISCUSSION}

This study investigated the influence of physical fitness on academy graduation, in addition to any differences between the sexes. Similar to Dawes et al. (10), this study also sought to ascertain if statistical models could be generated to predict a recruit's potential for graduating academy. The results from this study generally supported the study hypothesis and previous research $(10,25,42)$. Recruits that displayed superior fitness were more likely to graduate the academy. Even though the strength of correlations were generally small, they were similar to previous research investigating fitness relationships with law enforcement academy graduation and task performance $(5,10,31,38)$. This accentuates the application of the data analysis in this study to LEA staff. Interestingly, there were a wider range of fitness variables that appeared to influence academy graduation for all recruits combined and the males, and much fewer for the 
female recruits. These data could be influenced by the smaller sample size for females, in addition to the lower levels of fitness generally exhibited by females compared to males $(3,5,28,32)$. Given the cost associated with losing recruits during an academy $(39,42)$, the current data could impact strategies adopted to alleviate recruit attrition. Furthermore, sharing this information with candidates to a LEA may inform them of the risks associated having poorer fitness, and could also assist agencies with recruit selection (10).

The age, height, and body mass of the recruits in this study were typical of that established in the literature $(3,5,20-22,24,25,29-32)$. The WC and WHR values were also similar to that of law enforcement recruits (31). Despite a greater WC and WHR being linked to poorer fitness test performance (31), this study found no differences between GRAD and SEP groups, nor any significant relationships for WC and WHR. However, recruits who separated tended to be older, and age correlated with, and predicted, academy graduation. Previous research has shown that older law enforcement candidates have slower change-ofdirection speed measured by the 75PR, and lesser aerobic fitness measured by the $2.4-\mathrm{km}$ run (3). Lockie et al. (25) found that age was a predictor of recruits who separated from academy for academic or scenario-based failures, and Dawes et al. (10) also discovered recruits who separated were older than those who graduated. The results from this study supported this previous research and reemphasize the need for older recruits to achieve an acceptable level of physical fitness prior to academy $(3,25)$.

Several studies have indicated that recruits with lower levels of fitness are at greater risk of academy separation $(10,25,42)$. Dawes et al. (10) documented in police recruits that those who graduated were superior in push-ups and sit-ups completed in $60 \mathrm{~s}$, VJ height, and the 20MSFT. The results from this study supported Dawes et al. (10), with the addition of more fitness tests and a larger sample $(\mathrm{N}=311$ vs. $\mathrm{N}=99)$. The current results demonstrated that when considering both sexes combined, the GRAD group had superior change-of-direction 
speed (75PR), upper-body power (MBT), muscular endurance (push-ups, sit-ups, and arm ergometer), and aerobic fitness (20MSFT). When the male recruits were analyzed separately, in addition to the afore-mentioned fitness qualities, the GRAD group also had superior lowerbody power as measured by the VJ. A poorer $\mathrm{VJ}$ was linked to academy separation in recruits (10), and injury and illness in Australian recruits (37). Given the demands associated with physical training in academy $(21,25,39)$, it was expected that the GRAD group would be superior in the fitness tests used in this study. The data from this study highlight that recruits who start academy training with lower levels of fitness put themselves at greater risk of separating. Recruits should develop fitness qualities such as muscular endurance, upper- and lower-body power, running speed, and aerobic fitness prior to academy to enhance their ability to tolerate the challenges of academy training.

The prediction equations for all recruits combined and the males were similar, which was not surprising given the ratio between males $(n=260)$ and females $(n=51)$ in this study. For all recruits, aerobic fitness (20MSFT), upper-body power (MBT), and upper-body endurance (arm ergometer) were involved in predicting graduation. The prediction equation for the males featured upper-body power (MBT) and aerobic fitness (20MSFT). Academy training incorporates a range of physically demanding activities, including general conditioning, defensive tactics, and firearm and vehicle training $(7,21,25,38,39)$. The law enforcement-specific tasks completed during training (e.g. suspect pursuit and arrest, striking, grappling) would stress upper-body power and endurance, in addition to aerobic fitness. Further, aerobic fitness has been related to academy graduation in law enforcement recruits $(10,25,42)$, and performance in specific job tasks such as obstacle courses, foot pursuit simulations, and wall climbs (7,21). As noted by Dawes et al. (10), much more research is required to ensure that any standards developed based on these data are legally defensible. 
Nonetheless, these results show the benefits for a recruit to exhibit superior upper-body muscular endurance, in addition to aerobic fitness, to reduce the risk of separation.

For female recruits, only the arm ergometer differentiated between the GRAD and SEP groups, and correlated with graduation in females. Cesario et al. (5) noted that the arm ergometer provided a very specific measure of upper-body endurance in law enforcement recruits. Additionally, females, in general, tend to exhibit lesser relative upper-body strength compared to the lower-body, and the disparity is greater than that seen in males (34). It could be surmised that female recruits that have superior upper-body endurance or strength would stand out from females that do not, and this could influence their ability to graduate academy. The regression formula included the 20MSFT, in addition to the arm ergometer. As discussed, numerous studies have noted the importance of aerobic fitness for law enforcement recruits $(10,25,42)$. These data would suggest that upper-body endurance and aerobic fitness were qualities important for female recruits relative to graduation.

However, it should be acknowledged that most female recruits start academy training at a physical disadvantage compared to males $(3,5,28,32)$. Indeed, even for those females that graduated, they would still likely perform poorer in the fitness tests compared to most males. This supposition cannot be confirmed by the data from this study, but is an avenue for future law enforcement research. Further to this, even though this study included more females $(\mathrm{n}=$ 49) than Dawes et al. $(10)(n=10)$, the resulting sample of SEP females only represented $\sim 3 \%$ of the total sample. The lower number of females featured in this study could have confounded the results to a certain extent, especially considering the lower number of significant fitness differences between the GRAD and SEP groups. Nonetheless, a lesser number of female subjects is a common issue across all law enforcement research incorporating both sexes, given general disparity between the sexes in this profession $(3,5,20-22,24,25,27,29,31,32)$. Nonetheless, this also highlights why studies such as the current research are so important. As 
many agencies aim to hire and retain more women $(12,13,45)$, more research on females recruits must be produced to provide some basis for future directions and recommendations. Given the findings from previous research $(3,5,28,32)$, females should still attempt to enhance multiple aspects of physical fitness prior to academy. Moreover, with the need for upper-body actions during academy training (e.g. defensive tactics, striking, grappling, firearm training), female recruits should specifically attempt to develop upper-body endurance and strength. This is especially pertinent given that many females may have limitations in these qualities $(33,34)$.

Maximal dynamic strength was not measured in this study, and is not commonly measured or trained in law enforcement recruit populations (21). In actuality, the predominant measure of strength in this study (i.e. grip strength) did not differentiate between the GRAD and SEP groups, nor did it correlate or predict graduation among recruits. This was somewhat surprising, as grip strength has been shown to be important in law enforcement populations (38). Greater grip strength has been related to better marksmanship and performance in tactical operations (i.e. scenario-based training) (38). Future research should examine whether other strength tests could be used to delineate between GRAD and SEP recruits. For example, lowerbody strength could be useful to measure. In civilians, greater lower-body strength measured by the isometric mid-thigh pull related to faster $75 \mathrm{PR}$ performance (40), while a greater onerepetition maximum hexagonal bar deadlift correlated with a faster 165-lb (74.84-kg) body drag (26). Future research should incorporate maximal strength measures into analyses of recruit graduation, with some examples being a bench press for upper-body strength (6), hexagonal bar deadlift $(26)$, or leg/back dynamometer $(8,9)$ for trunk and lower-body strength.

Similar to Dawes et al. (10), it is likely that the prediction equations generated in this study may not be able to provide specific recommendations for fitness cut scores in recruits without extensive further research and validation (i.e. upwards of 10-20 academy classes required for analysis). This is important to recognize, as should LEA staff use equations such 
as those produced in this study in the candidate selection process, they must strive to limit any false negatives. This is where recruits would be predicted to fail but actually pass (10). Nevertheless, these equations, in addition to the current data collated, provide very useful information to law enforcement academy candidates and staff. Equations such as those produced in this study could be used to identify candidates that may experience greater challenges during academy, and who would be at a higher risk of academy separation. In accordance with this, candidates could then be informed of the risks associated with subpar levels of fitness during the hiring process (10). This could provide the opportunity for strength and conditioning practitioners working with LEAs to implement training interventions for candidates before they arrive at academy that could limit their chances of separation.

There are study limitations that should be discussed. Fitness characteristics can vary between different agencies (35). LEA staff should ideally investigate the fitness of their own recruits to ascertain characteristics that could influence graduation. It would be worth documenting whether changes in fitness after academy training, and the magnitude of change, influences graduation rates in recruits. This study did not differentiate recruits into reasons for separation (e.g. personal reasons, physical training failures or injury, academic or scenario failures) (25). Other law enforcement-specific skills which are tested during an academy, such as marksmanship and defensive tactics (38), were also not considered as a reason for separation. This could have influenced the results from this study. With a larger sample, future investigations should detail whether sex could influence reasons for separation in law enforcement recruits. The number of females $(n=49)$ analyzed relative to males $(n=259)$ was very different, although this is typical of law enforcement research $(3,5,20$ $22,24,25,27,29,31,32)$. Furthermore, the numbers in this study were greater than those from Dawes et al. (10), which allowed for the preliminary regression analyses. The sample incorporated recruits across four different classes. Although each class met the training 
requirements for the agency, the type of physical training may have varied; this could influence graduation and separation rates. Lastly, and as noted, future studies should attempt to include measures of maximal upper- (e.g. bench press) (6) and lower-body (e.g. hexagonal bar deadlift, leg/back dynamometer) $(8,9,26)$ strength to ascertain whether strength affects recruit graduation.

In conclusion, the results indicated that recruits who graduated from a law enforcement academy tended to be younger, and had superior upper- (MBT) and lower-body (VJ) power, faster change-of-direction speed (75PR), greater muscular endurance (push-ups, sit-ups, arm ergometer), and superior aerobic fitness (20MSFT). Graduation in all recruits was predicted by age, the 20MSFT (aerobic fitness), MBT (upper-body power), and arm ergometer (upper-body endurance). Graduation in male recruits was predicted by age, the MBT, and 20MSFT, while female recruit graduation was predicted by the arm ergometer and 20MSFT.

\section{PRACTICAL APPLICATIONS}

From the conclusions of this study, a number of practical applications can be drawn. Recruits should develop numerous physical fitness qualities prior to the academy. This includes upperand lower-body power, muscular endurance, running speed, and aerobic fitness. Specific to females, upper-body endurance was the only fitness measure that differentiated between the GRAD and SEP groups. However, this may also be related to the fact that females as whole will generally display lower levels of fitness relative to the male recruits. Female recruits should target multiple fitness qualities, although special attention could be paid to upper-body endurance and strength. The provision of this information to candidates for a LEA could allow for more effective physical preparation prior to their academy. Strength and conditioning practitioners could assist with the process of effectively preparing a candidate to become a law enforcement academy recruit. LEA staff could also use the information provided in this study, 
and the predictive equations, to assist with identifying recruits who may experience challenges during academy training and would be at a higher risk of separation. However, it should be noted that the predictive equations require further research to confirm whether they can correctly identify recruits who separate from an academy specific to this LEA.

\section{ACKNOWLEDGEMENTS}

This research project received no external financial assistance. None of the authors have any conflict of interest. The authors would like to thank the training instructors for facilitating this research, and the California State University, Fullerton tactical research team for collating the data.

\section{REFERENCES}

1. Aandstad, A, Holme, I, Berntsen, S, and Anderssen, SA. Validity and reliability of the 20 meter shuttle run test in military personnel. Mil Med 176: 513-518, 2011.

2. Beck, AQ, Clasey, JL, Yates, JW, Koebke, NC, Palmer, TG, and Abel, MG. Relationship of physical fitness measures vs. occupational physical ability in campus law enforcement officers. J Strength Cond Res 29: 2340-2350, 2015.

3. Bloodgood, AM, Dawes, JJ, Orr, RM, Stierli, M, Cesario, KA, Moreno, MR, Dulla, JM, and Lockie, RG. Effects of sex and age on physical testing performance for law enforcement agency candidates: Implications for academy training. J Strength Cond Res: doi:10.1519/jsc.0000000000003207, in press.

4. Callaghan, SJ, Lockie, RG, Andrews, WA, Chipchase, RF, and Nimphius, S. The relationship between inertial measurement unit-derived 'force signatures' and ground reaction forces during cricket pace bowling. Sport Biomech 19: 307-321, 2020. 
5. Cesario, KA, Dulla, JM, Moreno, MR, Bloodgood, AM, Dawes, JJ, and Lockie, RG. Relationships between assessments in a physical ability test for law enforcement: Is there redundancy in certain assessments? Int J Exerc Sci 11: 1063-1073, 2018.

6. Dawes, JJ, Orr, RM, Siekaniec, CL, Vanderwoude, AA, and Pope, R. Associations between anthropometric characteristics and physical performance in male law enforcement officers: A retrospective cohort study. Ann Occup Environ Med 28: 26, 2016.

7. Dawes, JJ, Lindsay, K, Bero, J, Elder, C, Kornhauser, C, and Holmes, R. Physical fitness characteristics of high vs. low performers on an occupationally specific physical agility test for patrol officers. J Strength Cond Res 31: 2808-2815, 2017.

8. Dawes, JJ, Orr, RM, Flores, RR, Lockie, RG, Kornhauser, C, and Holmes, R. A physical fitness profile of state highway patrol officers by gender and age. Ann Occup Environ Med 29: 16, 2017.

9. Dawes, JJ, Lockie, RG, Kornhauser, CL, Holmes, RJ, and Orr, RM. Relationships between absolute and relative strength and power in male police officers of varying strength levels. J Sci Sport Exerc 1: 281-288, 2019.

10. Dawes, JJ, Lockie, RG, Orr, RM, Kornhauser, C, and Holmes, RJ. Initial fitness testing scores as a predictor of police academy graduation. J Aust Strength Cond 27: 30-37, 2019.

11. Decker, A, Orr, RM, Pope, R, and Hinton, B. Physiological demands of law enforcement occupational tasks in Australian police officers. J Aust Strength Cond 24: 78-79, 2016.

12. Felkenes, GT, Peretz, P, and Schroedel, JR. An analysis of the mandatory hiring of females. Women Crim Justice 4: 31-63, 1993. 
13. Fernhall, B, Fahs, CA, Horn, G, Rowland, T, and Smith, D. Acute effects of firefighting on cardiac performance. Eur J Appl Physiol 112: 735-741, 2012.

14. Flueck, JL, Lienert, M, Schaufelberger, F, and Perret, C. Reliability of a 3-min all-out arm crank ergometer exercise test. Int J Sports Med 36: 809-813, 2015.

15. Garbarino, S, Cuomo, G, Chiorri, C, and Magnavita, N. Association of work-related stress with mental health problems in a special police force unit. BMJ Open 3: doi:10.1136/bmjopen-2013-002791, 2013.

16. Harris, C, Wattles, AP, DeBeliso, M, Sevene-Adams, PG, Berning, JM, and Adams, KJ. The seated medicine ball throw as a test of upper body power in older adults. $J$ Strength Cond Res 25: 2344-2348, 2011.

17. Hetzler, RK, Stickley, CD, Lundquist, KM, and Kimura, IF. Reliability and accuracy of handheld stopwatches compared with electronic timing in measuring sprint performance. J Strength Cond Res 22: 1969-1976, 2008.

18. Hopkins, W.G. A scale of magnitude for effect statistics, 2013. Available from: www.sportsci.org/resource/stats/index.html. Retrieved January 9, 2016.

19. Jeffriess, MD, Schultz, AB, McGann, TS, Callaghan, SJ, and Lockie, RG. Effects of preventative ankle taping on planned change-of-direction and reactive agility performance and ankle muscle activity in basketballers. J Sports Sci Med 14: 864-876, 2015.

20. Lockie, R and Hernandez, E. The 75-yard pursuit run performed by law enforcement recruits-Percentile rankings and implications for training TSAC Report 57: 16-22, 2020.

21. Lockie, RG, Dawes, JJ, Balfany, K, Gonzales, CE, Beitzel, MM, Dulla, JM, and Orr, RM. Physical fitness characteristics that relate to Work Sample Test Battery 
performance in law enforcement recruits. Int J Environ Res Public Health 15: 2477, 2018.

22. Lockie, RG, Dawes, JJ, Orr, RM, Stierli, M, Dulla, JM, and Orjalo, AJ. An analysis of the effects of sex and age on upper- and lower-body power for law enforcement agency recruits prior to academy training. J Strength Cond Res 32: 1968-1974, 2018.

23. Lockie, RG, Moreno, MR, Bloodgood, AM, and Cesario, KA. Practical assessments of power for law enforcement populations. TSAC Report 49: 6-12, 2018.

24. Lockie, RG, Stierli, M, Dawes, JJ, Cesario, KA, Moreno, MR, Bloodgood, AM, Orr, RM, and Dulla, JM. Are there similarities in physical fitness characteristics of successful candidates attending law enforcement training regardless of training cohort? J Trainol 7: 5-9, 2018.

25. Lockie, RG, Balfany, K, Bloodgood, AM, Moreno, MR, Cesario, KA, Dulla, JM, Dawes, JJ, and Orr, RM. The influence of physical fitness on reasons for academy separation in law enforcement recruits. Int J Environ Res Public Health 16: 372, 2019.

26. Lockie, RG, Balfany, K, Denamur, JK, and Moreno, MR. A preliminary analysis of relationships between a 1RM hexagonal bar load and peak power with the tactical task of a body drag. J Hum Kinet 68: 157-166, 2019.

27. Lockie, RG, Dawes, JJ, Kornhauser, CL, and Holmes, RJ. Cross-sectional and retrospective cohort analysis of the effects of age on flexibility, strength endurance, lower-body power, and aerobic fitness in law enforcement officers. J Strength Cond Res 33: 451-458, 2019.

28. Lockie, RG, Orr, RM, Stierli, M, Cesario, KA, Moreno, MR, Bloodgood, AM, Dulla, JM, and Dawes, JJ. The physical characteristics by sex and age for custody assistants from a law enforcement agency. J Strength Cond Res 33: 2223-2232, 2019. 
29. Lockie, RG, Dawes, JJ, Orr, RM, and Dulla, JM. Recruit fitness standards from a large law enforcement agency: Between-class comparisons, percentile rankings, and implications for physical training. J Strength Cond Res 34: 934-941, 2020.

30. Lockie, RG, Hernandez, JA, Moreno, MR, Dulla, JM, Dawes, JJ, and Orr, RM. 2.4-km run and 20-m multistage fitness test relationships in law enforcement recruits after academy training. J Strength Cond Res 34: 942-945, 2020.

31. Lockie, RG, Ruvalcaba, TR, Stierli, M, Dulla, JM, Dawes, JJ, and Orr, RM. Waist circumference and waist-to-hip ratio in law enforcement agency recruits: Relationship to performance in physical fitness tests. J Strength Cond Res 34: 1666-1675, 2020.

32. Lockie, RG, Dawes, JJ, Moreno, MR, Cesario, KA, Balfany, K, Stierli, M, Dulla, JM, and Orr, RM. Relationship between the 20-m multistage fitness test and 2.4-km run in law enforcement recruits. J Strength Cond Res: doi:10.1519/jsc.0000000000003217, in press.

33. Lovell, D, Mason, D, Delphinus, E, Eagles, A, Shewring, S, and McLellan, C. Does upper body strength and power influence upper body Wingate performance in men and women? Int J Sports Med 32: 771-775, 2011.

34. Monteiro, E, Brown, A, Bigio, L, Palma, A, Santos, L, Cavanaugh, T, Behm, D, and Corrêa Neto, V. Male relative muscle strength exceeds females for bench press and back squat. JEPonline 19: 79-85, 2016.

35. Myers, CJ, Orr, RM, Goad, KS, Schram, BL, Lockie, R, Kornhauser, C, Holmes, R, and Dawes, JJ. Comparing levels of fitness of police officers between two United States law enforcement agencies. Work 63: 615-622, 2019.

36. Orjalo, AJ, Lockie, RG, Balfany, K, and Callaghan, SJ. The effects of lateral bounds on post-activation potentiation of change-of-direction speed measured by the 505 test in college-aged men and women Sports 8: 71, 2020. 
37. Orr, R, Pope, R, Peterson, S, Hinton, B, and Stierli, M. Leg power as an indicator of risk of injury or illness in police recruits. Int J Environ Res Public Health 13: 237, 2016.

38. Orr, R, Pope, R, Stierli, M, and Hinton, B. Grip strength and its relationship to police recruit task performance and injury risk: A retrospective cohort study. Int J Environ Res Public Health 14: 941, 2017.

39. Orr, RM, Ford, K, and Stierli, M. Implementation of an ability-based training program in police force recruits. J Strength Cond Res 30: 2781-2787, 2016.

40. Post, BK, Dawes, JJ, and Lockie, RG. Relationships between tests of strength, power, and speed and the 75-yard pursuit run. $J$ Strength Cond Res: doi:10.1519/jsc.0000000000003398, in press.

41. Ryman Augustsson, S, Bersås, E, Magnusson Thomas, E, Sahlberg, M, Augustsson, J, and Svantesson, U. Gender differences and reliability of selected physical performance tests in young women and men. Advances in Physiotherapy 11: 64-70, 2009.

42. Shusko, M, Benedetti, L, Korre, M, Eshleman, EJ, Farioli, A, Christophi, CA, and Kales, SN. Recruit fitness as a predictor of police academy graduation. Occup Med 67: $555-561,2017$.

43. UCLA: Statistical Consulting Group. FAQ: What is dummy coding? 2020. Available from: $\quad$ https://stats.idre.ucla.edu/other/mult-pkg/faq/general/faqwhat-is-dummycoding/. Retrieved July 4, 2020.

44. World Medical Association. World Medical Association declaration of Helsinki. Recommendations guiding physicians in biomedical research involving human subjects. JAMA 277: 925-926, 1997.

45. Zhao, JS, He, N, and Lovrich, NP. Pursuing gender diversity in police organizations in the 1990s: A longitudinal analysis of factors associated with the hiring of female officers. Police Q 9: 463-485, 2006. 


\section{FIGURE LEGEND}

Figure 1: The dimensions for the 75-yard pursuit run in $\mathrm{m}(\mathrm{A})$ and the running direction (numbered in order; B). The barriers were $2.44 \mathrm{~m}$ long and $0.15 \mathrm{~m}$ high. 
Table 1: Descriptive data (mean \pm SD) for GRAD and SEP groups for all recruits combined.

\begin{tabular}{cccc}
\hline & GRAD $(\mathrm{n}=269)$ & SEP $(\mathrm{n}=42)$ & $p$ \\
\hline Age (years) & $26.78 \pm 5.12$ & $32.05 \pm 9.15^{*}$ & 0.001 \\
Height (m) & $1.73 \pm 0.09$ & $1.70 \pm 0.08$ & 0.039 \\
Body Mass (kg) & $80.26 \pm 13.55$ & $76.47 \pm 14.73$ & 0.097 \\
WC (cm) & $88.29 \pm 13.55$ & $87.31 \pm 13.44$ & 0.590 \\
WHR & $0.90 \pm 0.09$ & $0.91 \pm 0.09$ & 0.629 \\
Grip Strength (kg) & $81.03 \pm 23.04$ & $73.88 \pm 20.51$ & 0.052 \\
VJ (cm) & $53.44 \pm 12.63$ & $48.35 \pm 12.69$ & 0.016 \\
75PR (s) & $16.97 \pm 1.30$ & $17.87 \pm 1.20^{*}$ & $<0.001$ \\
MBT (m) & $5.92 \pm 1.21$ & $5.14 \pm 1.11^{*}$ & $<0.001$ \\
Push-ups (no.) & $44.59 \pm 15.40$ & $35.26 \pm 13.29^{*}$ & $<0.001$ \\
Sit-ups (no.) & $35.96 \pm 9.09$ & $30.57 \pm 8.28^{*}$ & $<0.001$ \\
Arm Ergometer (revs.) & $132.39 \pm 21.00$ & $119.48 \pm 22.26^{*}$ & $<0.001$ \\
20MSFT (shuttles) & $58.19 \pm 18.80$ & $43.70 \pm 14.25^{*}$ & $<0.001$ \\
\hline
\end{tabular}

* Significantly $(p<0.01)$ different from GRAD group.

WC: waist circumference; WHR: waist-to-hip ratio; VJ: vertical jump; 75PR: 75-yard pursuit run; MBT; medicine ball throw; 20MSFT; 20-m multistage fitness test. 
Table 2: Descriptive data (mean \pm SD) for GRAD and SEP groups for male recruits.

\begin{tabular}{cccc}
\hline & GRAD $(\mathrm{n}=228)$ & SEP $(\mathrm{n}=32)$ & $p$ \\
\hline Age (years) & $26.73 \pm 5.14$ & $32.81 \pm 9.90^{*}$ & 0.002 \\
Height (cm) & $1.75 \pm 0.08$ & $1.73 \pm 0.06$ & 0.107 \\
Body Mass (kg) & $83.34 \pm 11.95$ & $80.67 \pm 14.24$ & 0.248 \\
WC (cm) & $89.78 \pm 10.07$ & $88.94 \pm 14.46$ & 0.675 \\
WHR & $0.91 \pm 0.08$ & $0.91 \pm 0.05$ & 0.952 \\
Grip Strength (kg) & $86.05 \pm 20.83$ & $79.79 \pm 18.80$ & 0.109 \\
VJ (cm) & $56.08 \pm 11.02$ & $52.07 \pm 11.50^{*}$ & $<0.001$ \\
75PR (s) & $16.73 \pm 1.21$ & $17.58 \pm 1.07^{*}$ & $<0.001$ \\
MBT (m) & $6.27 \pm 0.95$ & $5.54 \pm 0.86^{*}$ & $<0.001$ \\
Push-ups (no.) & $48.15 \pm 13.23$ & $38.50 \pm 12.53^{*}$ & $<0.001$ \\
Sit-ups (no.) & $36.82 \pm 9.11$ & $31.31 \pm 8.72^{*}$ & 0.001 \\
Arm Ergometer (revs.) & $136.27 \pm 19.49$ & $126.53 \pm 20.59^{*}$ & 0.009 \\
20MSFT (shuttles) & $59.19 \pm 19.10$ & $43.36 \pm 15.01^{*}$ & $<0.001$ \\
\hline
\end{tabular}

* Significantly $(p<0.01)$ different from GRAD group.

WC: waist circumference; WHR: waist-to-hip ratio; VJ: vertical jump; 75PR: 75-yard pursuit run; MBT; medicine ball throw; 20MSFT; 20-m multistage fitness test. 
Table 3: Descriptive data (mean \pm SD) for GRAD and SEP groups for female recruits.

\begin{tabular}{cccc}
\hline & GRAD $(\mathrm{n}=41)$ & SEP $(\mathrm{n}=10)$ & $p$ \\
\hline Age (years) & $27.10 \pm 5.07$ & $29.60 \pm 5.95$ & 0.182 \\
Height (cm) & $1.62 \pm 0.05$ & $1.61 \pm 0.07$ & 0.832 \\
Body Mass (kg) & $63.10 \pm 7.92$ & $63.05 \pm 5.27$ & 0.986 \\
WC (cm) & $0.80 \pm 0.09$ & $0.82 \pm 0.08$ & 0.475 \\
WHR & $0.85 \pm 0.11$ & $0.90 \pm 0.17$ & 0.281 \\
Grip Strength (kg) & $53.13 \pm 12.35$ & $54.12 \pm 11.93$ & 0.820 \\
VJ (cm) & $38.78 \pm 10.90$ & $36.45 \pm 8.45$ & 0.531 \\
75PR (s) & $18.31 \pm 0.95$ & $18.79 \pm 1.17$ & 0.181 \\
MBT (m) & $4.03 \pm 0.61$ & $3.87 \pm 0.80$ & 0.490 \\
Push-ups (no.) & $24.78 \pm 11.05$ & $24.90 \pm 10.34$ & 0.975 \\
Sit-ups (no.) & $31.15 \pm 7.34$ & $28.20 \pm 6.46$ & 0.251 \\
Arm Ergometer (revs.) & $110.83 \pm 15.37$ & $96.90 \pm 7.40^{*}$ & 0.008 \\
20MSFT (shuttles) & $52.61 \pm 16.13$ & $44.80 \pm 12.15$ & 0.159 \\
\hline Significanty (p<0.01) & & \\
\hline
\end{tabular}

* Significantly $(p<0.01)$ different from GRAD group.

WC: waist circumference; WHR: waist-to-hip ratio; VJ: vertical jump; 75PR: 75-yard pursuit run; MBT; medicine ball throw; 20MSFT; 20-m multistage fitness test. 
Table 4: Correlations between separation and age, height, body mass, WC, WHR, and physical fitness in all recruits $(\mathrm{N}=311)$, males $(\mathrm{n}=260)$, and females $(\mathrm{n}=51)$.

\begin{tabular}{cccc}
\hline & All Recruits & Males & Females \\
\hline Age & $0.296^{* *}$ & $0.321^{* *}$ & 0.190 \\
Height & $-0.117^{*}$ & -0.100 & -0.030 \\
Body Mass & -0.094 & -0.072 & -0.003 \\
WC & -0.031 & -0.026 & 0.102 \\
WHR & 0.027 & 0.004 & 0.154 \\
Grip Strength & -0.110 & -0.100 & 0.033 \\
VJ & $-0.137^{*}$ & -0.118 & -0.090 \\
75 PR & $0.233^{* *}$ & $0.230^{* *}$ & 0.190 \\
MBT & $-0.218^{* *}$ & $-0.245^{* *}$ & -0.099 \\
Push-ups & $-0.207^{* *}$ & $-0.235^{* *}$ & 0.004 \\
Sit-ups & $-0.201 * *$ & $-0.196^{* *}$ & -0.164 \\
Arm Ergometer & $-0.205^{* *}$ & $-0.161^{* *}$ & $-0.368 * *$ \\
20MSFT & $-0.262^{* *}$ & $-0.269^{* *}$ & -0.200 \\
\hline$*$ Significant $(p<0.05)$ & & & \\
\hline
\end{tabular}

\footnotetext{
* Significant $(p<0.05)$ relationship between graduation/separation and the test variable.

** Significant $(p<0.01)$ relationship between graduation/separation and the test variable.

WC: waist circumference; WHR: waist-to-hip ratio; VJ: vertical jump; 75PR: 75-yard pursuit run; MBT; medicine ball throw; 20MSFT; 20-m multistage fitness test.
} 